\title{
Influence of ethical behavior on Corporate Governance of firm's performance in Ghana.
}

\author{
Obeng Kwakye ${ }^{1}$, Kong Yusheng ${ }^{2}$, Ayamba Emmanuel Caesar ${ }^{3}$, Agyemang Andrew Osei $^{4}$ \\ School of Finance and Economics, Jiangsu University, Zhenjiang, China
}

\begin{abstract}
This study aims at analyzing the influence which ethical behavior has on the corporate governance of firms performance in Ghana. The existing of ethical issues in business organizations and the general code of conduct which these companies are supposed to follow has brought about the need for researchers to assess their implications to the management of these firms. The findings in this study are essential in acknowledging the impact of ethical behavior on the management of the organization. This study has given us an in-depth understanding of the effects of ethical attributes such as ethical leadership and corporate governance to the overall financial development and performance of an firms in Ghana
\end{abstract}

Keywords: Ethical behavior, Ethical leadership, Corporate Governance, Performance, Organization

\section{Introduction}

Firms' ethical issues are basically the approaches or ways which the stakeholders of the firms use in managing the collective action from the majority point of view and avoiding the damaging actions by ensuring proper control measures are put in place to control the powers, authorities and responsibilities of the management. The ethical behavior of firms regards their relationship with the customers, the environment in which they operate and the employees. Establishing the influence which this ethical behavior has on the corporate governance of the firms is essential not only for academicians but also for the policy makers in the corporate level to understand its impact. The corporate governance principles are significant in the management of the organizations.

Currently, the global business environment is facing an increasing influence of ethical behaviors on the principles of corporate governance. The recent global scandals in various multinational firms are linked to the increased calls for the strengthening of the corporate governance practices. The frauds in these organizations have been immensely linked to the failure by the political governing authorities to implement without favor the principles of corporate governance.

According to Agyemang, Aboagye, \& Ahali (2013), Ghana is classic model when it comes to failure by the state to effectively implement the regulations and laws which govern the corporate governance affairs. When such laws and regulations are being implemented, the authorities either overlook on some issues or generally they are deliberately ignored. In the emergent economies like Ghana, exemplary corporate governance policies and practices are the vital instruments which have the potential in helping the firms achieve greater goals and maintain sustainability in the competitive market. With the increased both national and global competition, the business organizations tend to come up with uncouth methods of dealing with their competitors, characterized by illegal deals, failure to disclose all of their assets among others. According to Agyemang \& Castellini (2012), corporate governance is defined as the application of micro-policy strategies in the company with an aim of ensuring that heir is effective and efficient use of the firm's resources in order to achieve the goals and objectives of the company as well us succeed in the market which is competitive, maximize the profits and at the same time minimize the possible losses. While the corporate governance aspect deals with the micro-policy aspects of the firm, the ethical behavior deals with the firm's behavior when it interacts with the environment, information users and the general society in which they operate Ienciu (2012). 
According to the study conducted by Schwartz (2012), the business ethics based on the perception of the managers is associated with aspects like the ability to differentiate good and bad, acting in the adequate and correct manner, avoid deviances, have proper behavior, act professionally, be responsible and treat every person properly. The ethical issues in any organization are well understood by viewing the unethical conduct of the management or the employees' in a given context. The non-ethical behavior includes theft, discrimination, lack of transparency and confidentiality, favoritism, advertisements that are deceitful and concealments of the financial indicators among others. The ethical behavior in any given company according to Ienciu (2012) are the opposite of unethical behavior and they have impact on the corporate governance of the organization. In fact Alzola (2011) argues that, the reputation of any organization is an important asset which should not be tempered with. As early as 1996, scholars had already started to examine the correlation which exists between the financial performance of an organization and the ethical behavior it portrays. From the study done by Pava \& Krausz (1996), it was established that, companies which had been acknowledged as those with positive ethical conduct and are socially responsible experienced improved performance in their finances. In this case, ethical behavior is essential for the operations of the company as it influences the relationship which exists between the firm at its respective shareholders including clients, investors, suppliers and most importantly, the employees. Although the ethical conduct of the firm does not necessarily leads to the establishment of new performance, however, the unethical conduct seriously affects the long term performance of the company Ienciu (2012).

Ethical issues in profit making organizations have been in the center of academic scholarly research for the past years. The continuous power struggle, and court cases involving the multinational firms across the world and especially in Ghana, necessitated this research to establish the influence which ethical behavior has on the corporate governance strategy. The positive ethical elements require the firms to practice transparency in their financial reporting. Corporate governance requires the companies to stick with the best governing principles which will ensure that the operations of the organization are at par. Various scholarly studies have mainly dwelt their research studies on the relationship which exists between the ethical behavior of the company and the employee motivation, performance of the firm and profitability. Other studies have dwelt on the influence of proper corporate governance in the in the profitability of the firm. Few studies have been documented on the influence of ethical behavior to the corporate governance of an organization. Thus, this study aims at assessing the influence of ethical behavior on corporate governance in Ghana.

The general research objective of this study is to assess the influence of ethical behavior on corporate governance in Ghana. Ethical behavior of an organization affects the motivation of the employees and the financial performance of the company. However, the specific objectives include determining the extent to which the ethical behavior is a significant factor in corporate governance, assessing the determinants of ethical behavior in an organization and determining the benefits of ethical behavior in the performance of the company. The need to examine the influence of ethical behavior to the corporate governance in Ghana is essential topic that establishes the fundamental principles which has to be followed by corporate organizations in fulfilling their mandate. Establishing the link between ethical behavior and corporate governance is essential in helping the corporate policymakers to bring up the needed recommendations for the effectiveness and efficiency of the company. The findings in this study are essential in acknowledging the impact of ethical behavior on the management of the organization. It will also help in establishing the link which exists between the two variables.

\section{Literature review}

In any given organization, ethics plays an integral role in ensuring good governance and also has a potential of affecting the trust which the public has to an organization in terms of its governance Perry et al (2014). Based on the previous scholarly research studies, various factors have been examined as the key components which have a significant effect on the ethical behavior of a firm. Among the key component according to Grojean, Christian, Dickson, \& Brent (2004), is the role of leadership in the organization. According to Downe, Cowell, \& Morgan (2016), the ethical behavior of a leader is an essential concept which has played an integral role in the global corporate governance of many organizations. Many scandals incriminating the leaders of the organizations are based on the lack of integrity and ethics, either in financial reporting or on how they treat their employees. 
Various studies are investigating the positive impact of ethical leadership and the impact it has on the performance of the employees. This is because, studies show that, the increased trust of employees to the management of the company has the potential of improving their job satisfaction, which can lead to improved performance of the company in terms of productivity Hassan (2015). According to Menzel (2007), the analysis of the role of leadership style in fostering the ethical behavior of an organization has remained underdeveloped. However, it is widely renowned that, the leaders can exert influence to the employees and consequently affect the corporate governance structure of the organization. Given the little research conducted on this topic, it is essential to analyze the impact of leadership on the ethical behavior of the company.

\section{Determinants of Ethical Behavior}

According to Bello (2012), the most recorded ethical issues in continental Europe includes corruption, discrimination, facilitation payment and corruption. This can be exemplified by the Texaco case in 1996 where the company made a whopping settlement of $\$ 176$ million for racial discrimination. Mitsubishi in 1998 paid \$34 million due to sexual harassments investigations carried out by the government. Apart from the cases from the industrialized firms, the developing nation's companies are not left behind, Nigeria, for instance, reported various cases or organizational fraud and failed ethical management Bello (2012). In 1997, 26 commercial banks in Nigeria failed due to financial irregularities. According to Brown and Mitchell 2010, ethics must start from the top of the hierarchy. Leaders have to set a moral example to the subordinates. In fact Bello (2012) argues that training and formal codes and regulations of ethics in an organization play insignificant role in shaping the ideal corporate governance unless the ethical actions emanate from the top and the leadership is consistent with what they teach. When it comes to the organizational goals and objectives of the company, leaders are the key determinants and they influence the operations of the organization in order to attain the set goals.

The encouragement from the leadership on moral, ethics and corporate governance should be example based. According to Fisher \& Lovell (2003), a negative behavioral example from the leaders is like cancer to the ethics of an organization. In fact, Crane and Crane \& Matten (2007) confirms that, if the leaders are portrayed as inconsiderate and ruthless, the employees will also adopt this type of style in administering their duties in the day to day life. Kouzes \& Posner (2007) argues that, the employees want to be related to honest, respectful, fair and credible managers. In fact, Upaadhyay \& Singh (2010) argues that the organization can lower the turnover rate of employees and improve the retention rate by ensuring that the workers have a chance of working with the managers that are honest, credible, fair and ethical. Failure by the leadership to show good morals and ethical behavior can lead to increased turnover rate and also decreases the likelihood of attracting credible and competent employees from the labor market. The ethical behavior portrayed by the leadership reduces the costs associated with recruiting and training new employees Bello (2012).

Ho: There exists no significant influence of ethical leadership to the ethical conduct of an organization.

\section{Influence of ethics to organizational performance}

Oladele (2010), established the relationship which exists between the ethical behavior in an organization and the general performance of the firm. The study defined ethical behavior as a set of moral principles which are utilized by the company with an aim of steering the conduct of the employees, firm and all the stakeholders. According to Oladele (2010), the ethical behavior has a significant influence on the performance of the organization. In fact, it affects the performance, motivation, and productivity of the employees. The study further established that good ethical behavior is positively correlated with the performance of a given organization. Thus, firms should adopt those measures, behavior, and principles which shape their ethics positively, as this will lead to improved profitability. Further, Akhavan, Ramezan, Moghaddam, \& Mehralian (2014) proved that there is a strong positive correlation which exists between the ethics of an organization with the firm's performance. According to Saeidi \& Bidi (2012), the ethical principles have to be implemented in various stages of the organization to ensure that the decision-making process is based on evidence and facts and not bias or discrimination. Ethics affects the performance of the employees, for this reason, it is important to study the topic.

According to Selvarajan \& Sardessai (2010), in the performance appraisal of the employees in the organization should be based on the ethics of the company. According to Saeed, Shakeel, \& Lodhi (2013) 
applied a regression analysis where ethical values were measured as the independent variable and dependent variable wad the performance of the workers. With a sample size of 150 , it was established that ethical behavior affects the performance of the employees in a positive way. Also, Sabir, et al. (2012) found that the corporate ethical values are an essential factor when it comes to the ethical leadership and the performance of the employees. The two variables, corporate ethics, and ethical leadership have the augmentative effect on the overall productivity and performance of the company. Therefore, it is hypothesize that:

Ho: Good ethical attributes has no positive influence on the financial performance of the company.

\section{Ethical Behavior and Corporate Governance}

The primary goal and objective of any organization are to increase the value of the shareholder's input. The achievements of these goals and objectives must be done within the set, acceptable and environmentally friendly principles. According to McKay, Nitsch, \& Peters (2015), ethical behavior affects the principles which guide the governance of the cooperation. Positive ethical behavior will definitely lead to acceptance of positive, transparent and nondiscriminatory corporate governance principles. According to the study conducted by Ienciu (2012), the code of ethics in an organization are the rules of conduct, principles, philosophy and the code of practice which directs the relationship between the company and the shareholders. The attitude of the management plays a significant role in the ethical behavior of the firm. This is because the management is the vital actor in the company whose actions have direct implications on the day to day operation of the firm. Booth \& Schulz (2004), describes the agency theory based on the managers need to maximize the private interest rather than the universal organizational goal.

Ho There exists no significant relationship between ethical behavior and corporate governance.

\section{Factors Affecting Ethical Behavior}

Corporate governance works by interfering with the agency theory notion and ensures that the management acts according to the interests of the shareholders Solomon (2007). According to the theory of stakeholders, corporate governance provides the firm with universal direction through control and supervision. Besides, the social responsibility of the firm depends entirely on the corporate governance of the company as a management strategy. Therefore, according to Ienciu (2012), business ethics and ethical behavior influence corporate governance in various ways. Good ethical behavior improves the corporate governance process and poor ethical behavior deteriorates the corporate governance. Therefore, based on the literature, ethical behavior is a significant factor in corporate governance. Aspects including corruption, facilitation of payment and discrimination are the key practices that affect ethical behavior in the organization.

$H_{o}$ Corruption, discrimination, and facilitation payment have no significant impact on ethical behavior

\section{Methodology}

The variation and causative effects of different variables related to a study are well analyzed and understood using appropriate research methodology that depicts effective statistical techniques. In this study, effective methods were needed to show the effects of ethical behavior, ethical leadership, corporate governance to the corresponding financial performance and growth of the company. This study involved research on a sample of individuals from 200 different companies indicating their ethical traits, leadership traits and the general performance. Other ethical factors such as corruption and racial discrimination were considered and were needed to be compared with the companies' financial performance. The data was collected by means of both primary and secondary sources. The primary data was directly collected from respondents from the two hundred different companies while the secondary data was important for knowing the background of the study as stipulated in the literature review. The secondary sources such as books, scientific published papers and journals also depicted the results, data and findings made from previous studies in reference to the ethical behaviors and its effects to the development and improved financial performance.

The set of hypothesis indicates that the relationship between the variables should be tested using different statistical techniques. The descriptive statistical analysis is very vital in showing the general characteristics of variables in the dataset. Simpler association analysis between variables is described using scatterplots.

However, the most relevant measures important for showing the nature of relationship between the factors attributing to improved financial performance of the companies are the correlation and regression analysis. The correlation analysis is the measure of the strength of relationship or association between 
different variables. The relationship between variables is referred to as either strongly positive or strongly negative. This depends on the value of the correlation coefficient; when the coefficient is positive and close to 1 , the relationship is referred to as strongly positive associations while the association when the correlation coefficient is negative and far from 1 , it is referred to as strongly negative. The significance of the relationships can be confirmed using the regression analysis. Regression analysis entails linear relationship between one or multiple variables. The regression analysis is very applicable in creating econometric models corresponding to different business structures. Regression econometric models are created using different predictor variables in the study in reference to the response variable under consideration. Each regression model has a corresponding histogram and a normal probability plot.

\section{Model Specification \& Variables.}

The multivariate regression model involving many variables is explained in this part. The econometric model can be described using the following equation:

Financial Performance $=\beta 0+\beta 1 G E B_{p q}+\beta 2 E L_{p q}+\beta 3 C G_{p q}+\beta 4 C I O_{p q}+\beta 5 R D O_{i t}+\varepsilon_{p q}$

Where:
GEB $=$ Good ethical behaviors
$\mathrm{EL}=$ Ethical Leadership.
$\mathrm{CG}=$ Corporate Governance.
$\mathrm{CIO}=$ Corruption in your Organization .
$\mathrm{RDO}=$ Racial Discrimination in your Organization .
$\mathrm{E}=$ is error term
$\beta 0=$ Constant
$\mathrm{p}=$ represents the companies
$\mathrm{q}=$ represents the years

\section{Variables}

The above variables stipulated on the econometric model will be considered in the analysis. The response variable also referred to as the dependent variable is the financial performance. The predictor variables or the independent variables include; good ethical behaviors, ethical leadership, corporate governance, corruption in the organization and racial discrimination. The dataset contains more variables such as gender, age of the respondents, education level and good payment facilitation modes in different organizations. The variation between the variables can be observed by pairing both response and predictor variables and observations are made indicating whether the variables influence each other positively or negatively. The variables in the model are considered because in the previous studies, they have been evidently used to explain business financial growth and development over specified periods. In cases of further regression analysis, the control variables or the mediation variables used to explain relationship between variables in reference to different mediation effects include age and gender, in comparison to financial performance and the good ethical attributes.

\section{Results \& Findings}

Table 1: Descriptive Statistics of Variables

Descriptive Statistics

\begin{tabular}{|l|r|r|r|r|r|r|r|r|r|}
\hline & $\begin{array}{c}\text { Observ } \\
\text { ations }\end{array}$ & $\begin{array}{c}\text { Minimu } \\
\mathrm{m}\end{array}$ & $\begin{array}{c}\text { Maximu } \\
\mathrm{m}\end{array}$ & Mean & \multicolumn{2}{c|}{$\begin{array}{c}\text { Std. } \\
\text { Deviatio } \\
\mathrm{n}\end{array}$} & \multicolumn{2}{|c|}{ Skew-ness } & \multicolumn{2}{|c|}{ Kurtosis } \\
\cline { 2 - 10 } & Statistic & Statistic & Statistic & Statistic & Statistic & $\begin{array}{c}\text { Statis } \\
\text { tic }\end{array}$ & $\begin{array}{c}\text { Std. } \\
\text { Error }\end{array}$ & Statistic & $\begin{array}{c}\text { Std. } \\
\text { Error }\end{array}$ \\
\hline EL & 19 & 1 & 3 & 2.05 & .848 & -.107 & .524 & -1.623 & 1.014 \\
ClO & 20 & 1 & 5 & 2.20 & 1.240 & .685 & .512 & -.447 & .992 \\
RDO & 20 & 1 & 5 & 2.20 & 1.196 & .803 & .512 & -.063 & .992 \\
GEB & 20 & 2 & 5 & 3.95 & 1.050 & -.498 & .512 & -1.001 & .992 \\
CG & 19 & 1 & 4 & 2.05 & .970 & .294 & .524 & -1.139 & 1.014 \\
Financial performance & 19 & 1269.00 & 7548.00 & 3817.368 & 1962.78 & .638 & .524 & -1.067 & 1.014 \\
& & & & & & & & & \\
\hline
\end{tabular}


The minimum and maximum values indicate the variables in the dataset. Any value not contained in the range is therefore easy to identify implying that these values are outliers. The mean and standard deviation for ethical leadership is approximately 2.05 and 0.848 respectively. This implies that it is not possible to have equality in means and variances. Therefore, it is averagely possible that the variables follow the normal distribution. The mean and variance for the corporate governance is approximately 2.05 and 0.970 which are not equal. The skew-ness and kurtosis measures are important in indicating the level of symmetry of the distribution of the variables in the dataset. The skew-ness and Kutorsis measures both indicates even distribution of the variables which means that the variables can be used to explain variation between them.

Table2: Correlation Analysis matrix:

\begin{tabular}{|l|r|r|r|r|r|r|}
\hline & \multicolumn{1}{|c|}{ Correlation Results } \\
& \multicolumn{1}{|c|}{ EL } & \multicolumn{1}{c|}{ CIO } & \multicolumn{1}{c|}{ RDO } & \multicolumn{1}{l|}{ GEB } & $\begin{array}{c}\text { Financial } \\
\text { performance }\end{array}$ & \multicolumn{1}{c|}{ CG } \\
\hline EL & 1 & -0.225 & -0.171 & 0.132 & -0.894 & 0.537 \\
CIO & -0.225 & 1 & 0.93 & -0.922 & 0.23 & 0.034 \\
RDO & -0.171 & 0.93 & 1 & -0.829 & 0.158 & -0.01 \\
MOG & 0.132 & -0.922 & -0.829 & 1 & -0.228 & -0.103 \\
Financial & -0.894 & 0.23 & 0.158 & -0.228 & 1 & -0.63 \\
performance & 0.537 & 0.034 & -0.01 & -0.103 & -0.63 & 1 \\
CG & &
\end{tabular}

The above results stipulate both positive and negative association between different pairs of variables. The fact remains that significant relationships exist between the variables despite the negativity or positivity of the correlation coefficients. For instance, the correlation coefficient between the financial performance and corruption in different organization is positive but quite far from 1. This implies there exists a weak positive association between financial performance of different organizations under study and corruption cases in the organization. Therefore, these variables can be used to significantly explain variation between each other. There also exists a positive relationship between financial performance and racial discrimination in the industries. This means that racial discrimination has a considerable effect on the overall financial performance of the institution, which implies that equal treatment despite the race should be advocated for to assist in improving performance

The correlation coefficient in Table 2 between corporate governance and ethical leadership is approximately 0.53 which indicates a strongly positive association between the given variables implying significant association. Similarly, highly positive correlation coefficient between corruption in the organizations and racial discrimination is observed (approximately 0.93).

This indicates a positive significant association between these factors which implies that it is possible that organizations that face the racial discrimination challenges also suffer corruption showing that the working environment is unethical which causes poor performance. This relationship will also be observed using the regression analysis.

\section{Regression results.}

The above model summary indicates quite interesting results. The R-squared statistic is approximately 0.89 . This means that there exists approximately $89 \%$ amount of variation between all the variables in the econometric regression model. Therefore, all the variables in the model can be used to explain variation between each other which confirms that the model is very significant.

Table 3: Regression Results 


\begin{tabular}{|c|c|c|c|c|c|c|}
\hline \multirow[b]{2}{*}{ Model } & & \multicolumn{2}{|c|}{$\begin{array}{c}\text { Unstandardized } \\
\text { Coefficients }\end{array}$} & \multirow{2}{*}{$\begin{array}{c}\begin{array}{c}\text { Standardiz } \\
\text { ed } \\
\text { Coefficient } \\
\text { s }\end{array} \\
\text { Beta }\end{array}$} & \multirow[b]{2}{*}{$\mathrm{t}$} & \multirow[b]{2}{*}{ Sig. } \\
\hline & & B & Std. Error & & & \\
\hline & (Constant) & 14339.49 & 2692.394 & & 5.326 & 0 \\
\hline & my ethical behavior is good & & & & & \\
\hline & & -1055.34 & 442.839 & -0.564 & -2.383 & 0.033 \\
\hline & $\begin{array}{l}\text { Is there racial discrimination in } \\
\text { your organization }\end{array}$ & -382.82 & 473.519 & -0.24 & -0.808 & 0.433 \\
\hline & Ethical leadership & & & & & \\
\hline & & -1769.28 & 270.112 & -0.765 & -6.55 & 0 \\
\hline & $\begin{array}{l}\text { Is there corruption in your } \\
\text { organization }\end{array}$ & -354.128 & 643.528 & -0.224 & -0.55 & 0.591 \\
\hline & Corporate governance & -551.737 & 227.237 & -0.273 & -2.428 & 0.03 \\
\hline & R Square & 0.894 & & & & \\
\hline & Adjusted R Square & 0.856 & & & & \\
\hline
\end{tabular}

Figure 1: Histogram corresponding to the regression analysis

Histogram

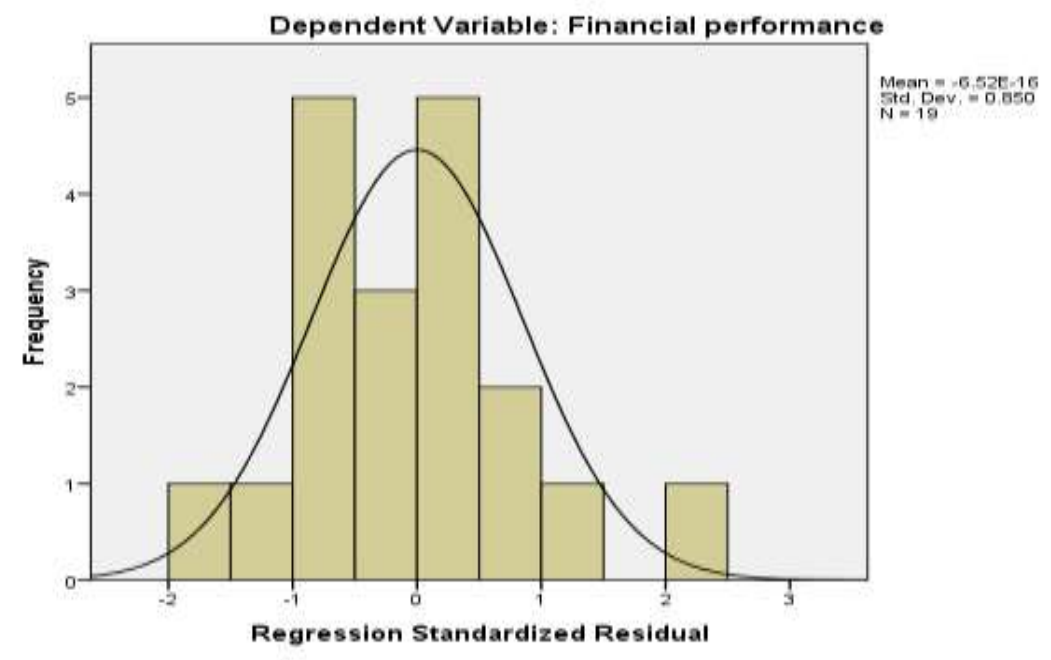

Figure 2: Normal probability plot corresponding to the regression analysis 


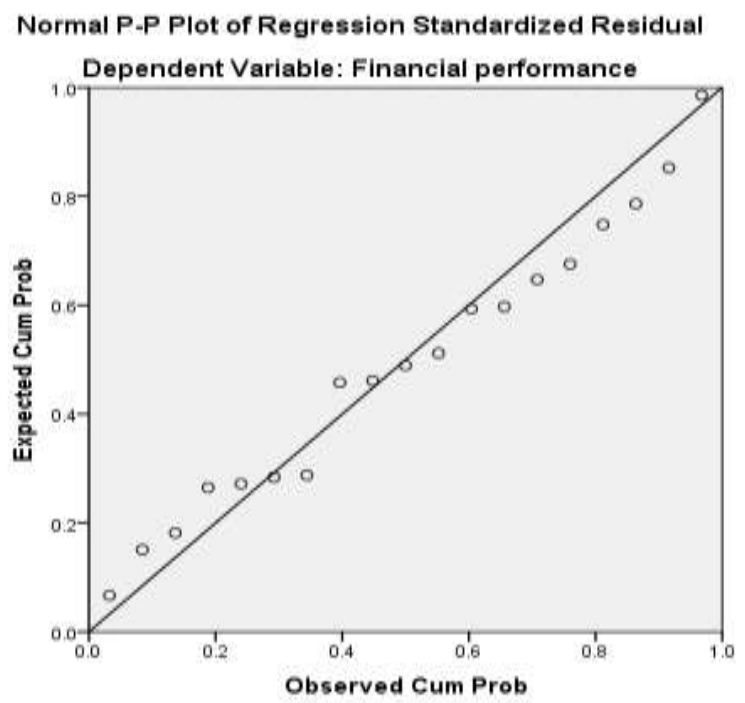

The above histogram and normal probability approximates the normal distribution which is one of the most applicable probability distribution. This is shown by the Gaussian curve demonstrated on the histogram and the normal curve implying equality in means and variances between the most important variables in the data under consideration. The normal probability plot shows significance of the relationship because the dots are aligned in a linear form indicating a good relationship between the variables since it means that the data approximates the normal distribution

Figure3: Scatterplot on Financial performance and corporate governance

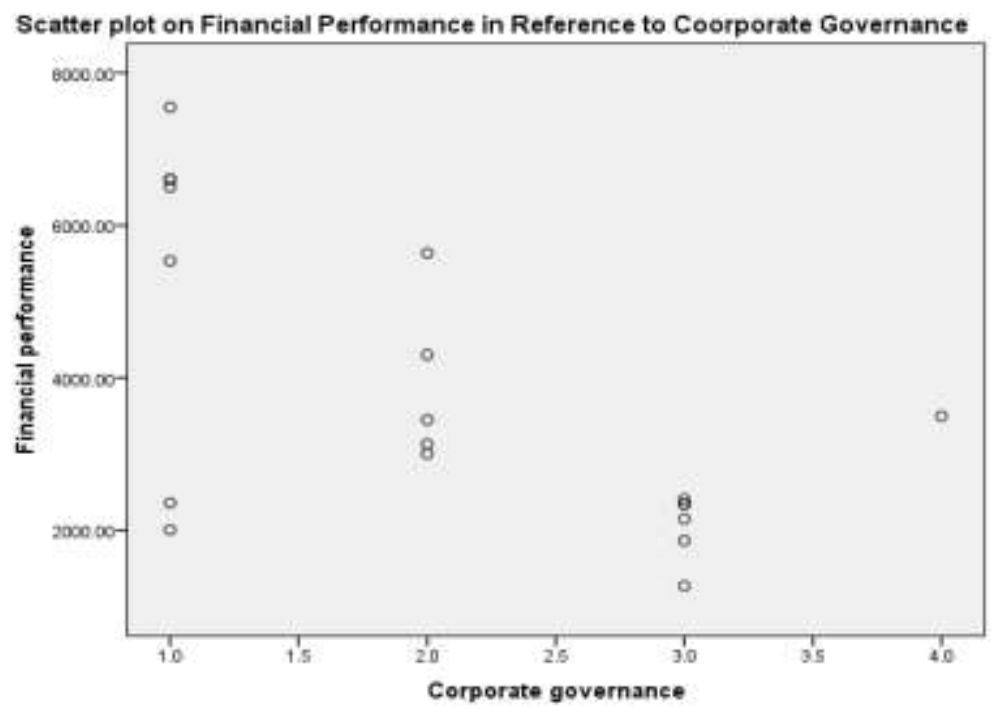

Figure4: Scatterplot on Financial performance and corporate governance 


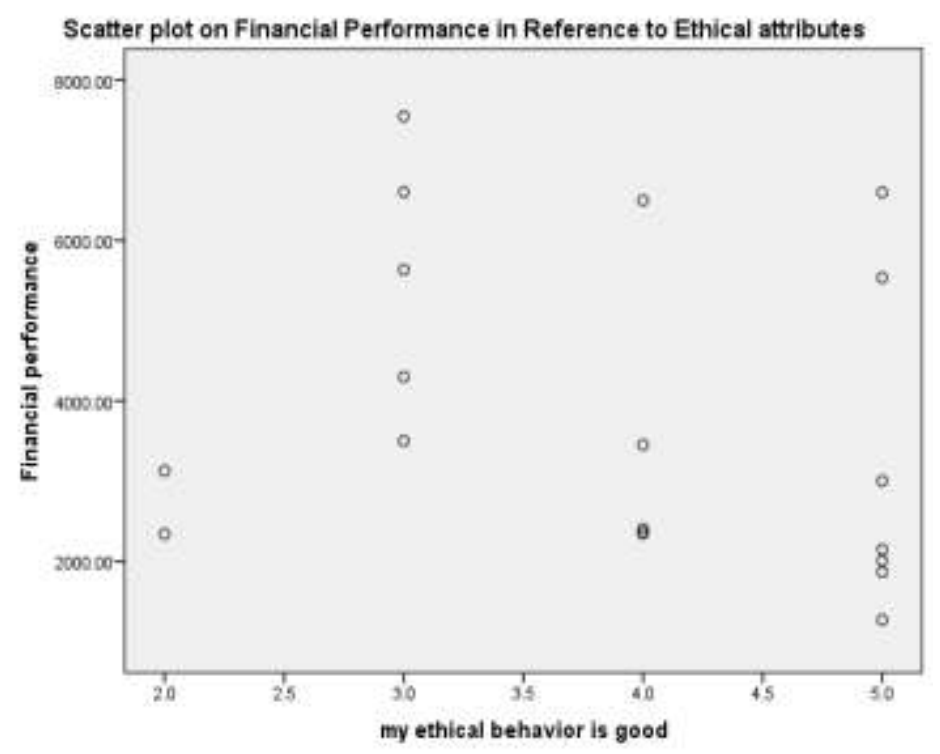

The above scatterplots do not show effective association between the variables explained, but a vague association between the pair of factors is observed indicating a considerable amount of variation between the pairs.

\section{Discussion}

Data analysis is a very important aspect of scientific research since it breaks down data in simple and more visually appealing illustrations. Since the econometric model considered is significant, it implies that all the causative factors of the financial performance should be considered in-order to promote the growth of different organization over different fiscal years. The attributes that were specifically significant such as the ethical attributes, corporate governance, and ethical leadership are a good basis for improvements and further study. Thus, the business practitioners should embrace the effective ethical attributes, corporate governance and ethical leadership in order to improve the well-being of the organizations.

The above regression results (Table 3) indicate a significant econometric model in reference to the set of hypothesis. The different sets of hypothesis are evaluated and interpreted in reference to the $p$-value represented as significant values on table above. Taking the first hypothesis: Null Hypothesis: There exists no significant influence of ethical leadership to the ethical conduct of an organization. The ethical factors such as ethical leadership and good ethical behavior indicated on the table above have a p-value approximately 0.033 and 0.000 which are less than the statistically significance level $\alpha=0.05$. Therefore, the null hypothesis is rejected and we conclude that there exists a significance influence of ethical leadership to the overall ethical conduct of different organizations under study. Similarly, the second hypothesis was considered; Null Hypothesis: Good ethical attributes has no positive influence on the financial performance of the company. This hypothesis is rejected because the corresponding p-value approximately 0.033 which is also less than the statistical significance level which implies that there exists a significant association between good ethical attribute and the financial performance of the organizations. This confirms a considerable significant amount of variation between these variables. Considering the other hypothesis; Null Hypothesis: corruption, discrimination, and facilitation payment have no significant impact on ethical behavior. The p-values corresponding to the factors corruption and discrimination are approximately 0.59 and 0.433 which are greater than the statistical significance level 0.05 .

Therefore, the null hypothesis is accepted and we conclude that there exists no significant relationship between corruption and racial discrimination to the ethical behavior and effectively the total financial performance. The $\mathrm{p}$-value corresponding to corporate governance is approximately 0.030 which indicates significant association between corporate governance and financial performance. Similarly, the null hypothesis is rejected and we conclude that there exists a significant influence of corporate governance to the overall financial performance.

Generally all the vital attributes and variables are clearly depicting appropriate association in reference to the previous study and the analyzed results. 
The factors financial performance and good ethical behaviors indicate a negative association between the variables, which shows the negative effect of poor ethical attributes to decreased financial performance. The corporate governance aspect in reference to the corruption in the organization indicates a substantive positive association which implies that corporate governance is affected by unethical attributes such as corruption. The correlation matrix therefore proves to be a good basis for explaining variation and relationship between variables. However, the significance of the relationships can be confirmed using the regression analysis.

\section{Conclusions \& Recommendations}

In conclusion, this study has given us an in-depth understanding of the effects of ethical attributes such as ethical leadership and corporate governance to the overall financial development and performance of an organization. The factors and variables listed have proven to have a negative or positive effect to the business performance. This means that every variable in this dataset has an important implication on the growth and development of different business organizations.

The business practitioners should therefore use all the factors and variables associated to the financial performance to perform timely analysis on the effects of these variables. The ethical issues have proved to be a great concern because of its immense influence on the financial performance. Thus, the management should advocate and insist on effective ethical attributes from all members of staff. The leadership aspect in every organization is very vital in effective running of all departments of the organization, therefore excellent leadership qualities are very appropriate to enhance vigilant overseeing of all the departments of the organization.

Funding: National Natural Science Foundation of China (No. 71371087)

\section{References}

[1] Agyemang, O. S., \& Castellini, M. (2012). Ownership and Board Structures to Ensuring Effective Corporate Governance through Ownership and Board Control Systems. Corporate Ownership and Control, 336-343.

[2] Agyemang, O. S., Aboagye, E., \& Ahali, A. Y. (2013). Prospects and Challenges of Corporate Governance in Ghana. International Journal of Scientific and Research Publications, 1-9.

[3] Akhavan, P., Ramezan, M., Moghaddam, J. Y., \& Mehralian, G. (2014). Exploring the relationship between ethics, knowledge creation and organizational performance: Case study of a knowledgebased organization. The journal of information and knowledge management systems, 42-58.

[4] Alzola, M. (2011). The Ethics of Business in Wartime. Journal of Business Ethics, 61-71.

[5] Bello, S. M. (2012). Impact of Ethical Leadership on Employee Job Performance. International Journal of Business and Social Science, 227-236.

[6] Booth, P., \& Schulz, A. (2004). The impact of an ethical environment on managers' project evaluation judgments under agency problem conditions. Accounting, Organizations and Society, 473-488.

[7] Crane, A., \& Matten, D. (2007). Business Ethics. Managing Corporate Citizenship and Sustainability in the Age of Globalization. New York: Oxford University Press Inc.

[8] Downe, J., Cowell, R., \& Morgan, K. (2016). What Determines Ethical Behavior in Public Organizations: Is It Rules or Leadership? Public Administration Review, 898-909.

[9] Fisher, C., \& Lovell, A. (2003). Business Ethics and Values. Essex: Pearson Education Limited.

[10] Grojean, M. W., Christian, R. J., Dickson, M. W., \& Brent, S. D. (2004). Leaders, Values, and Organizational Climate: Examining Leadership Strategies for Establishing an Organizational Climate Regarding Ethics. Journal of Business Ethics, 223-241.

[11] Hassan, S. (2015). The Importance of Ethical Leadership and Personal Control in Promoting Improvement-Centered Voice among Government Employees. Journal of Public Administration Research and Theory, 697-719.

[12] Ienciu, I. A. (2012). Corporate Governance and Ethical Behavior: A National Perspective . The Romanian Economic Journal , 49-68.

[13] Ienciu, I. A. (2012). Corporate Governance and Ethical Behavior: A National Perspective. The Romanian Economic Journal , 49-68. 
[14] Kouzes, J. M., \& Posner, B. Z. (2007). The Leadership Challenge. Hoboken, NJ: JohnWiley \& Sons.

[15] McKay, D. R., Nitsch, R., \& Peters, D. A. (2015). Corporate governance and business ethics. Plast Surg, 272-272.

[16] Menzel, D. C. (2007). Ethics Management for Public Administrators: Building Organizations of Integrity. Armonk, NY: M. E. Sharpe.

[17] Oladele, J. K. (2010). Effect Of Ethical Behaviour on Organizational Performance: evidence from three Service Organizations In Lagos Nigeria. Journal of Research in National Development, Federal University of Technology.

[18] Pava, M., \& Krausz, J. (1996). The Association between Corporate Social-Responsibility and Financial Performance: The Paradox of Social Cost. Journal of Business Ethics, 321-357.

[19] Sabir, S. M., Iqbal, J. J., Rehman, K. U., Shah, K. A., Yameen, M., \& Yameen, M. (2012). IMPACT OF CORPORATE ETHICAL VAULUES ON ETHICALLEADERSHIP AND EMPLOYEE PERFORMNCE. International Journal of Business and Social Science, 163-171.

[20] Saeed, R., Shakeel, M., \& Lodhi , R. N. (2013). Ethical Behavior and Employees Job Performance in Education Sector of Pakistan. Middle-East Journal of Scientific Research, 524-529.

[21] Saeidi, P., \& Bidi, R. E. (2012). A Model To Improve Company Performance Through Business Ethics. International Journal On Social Science Economics and Arts, 2.

[22] Selvarajan, T. T., \& Sardessai, R. (2010). Appraisal Of Ethical Performance. A Theoratical Mode. The Journal Of Applied Business Research, 26.

[23] Solomon, J. (2007). Corporate Governance and Accountability. Business \& Economics.

[24] Upaadhyay, Y., \& Singh, S. K. (2010). In Favour of Ethics in Business: The Linkage between Ethical Behaviour and Performance. Journal of Human Value, 9-19. 